The Prostate 44:I I8-123 (2000)

\title{
Decreased Galectin-3 Expression in Prostate Cancer
}

\author{
Ronald A. Pacis, ${ }^{1}$ Mary Josephine Pilat, ${ }^{1}$ Kenneth J. Pienta, ${ }^{1,2 *}$ Kirk Wojno, ${ }^{1,3}$ \\ Avraham Raz, ${ }^{4}$ Victor Hogan, ${ }^{4}$ and Carlton R. Cooper ${ }^{1}$ \\ 'University of Michigan Comprehensive Cancer Center, Division of Hematology/Oncology, \\ Department of Internal Medicine, St. John's Hospital, Detroit, Michigan \\ ${ }^{2}$ Section of Urology, Department of Surgery, St. John's Hospital, Detroit, Michigan \\ ${ }^{3}$ Department of Pathology, St. John's Hospital, Detroit, Michigan \\ ${ }^{4}$ Karmanos Cancer Institute and Wayne State University, Detroit, Michigan
}

\begin{abstract}
BACKGROUND. Galectin-3 is a carbohydrate-binding protein whose level of expression has been shown to be correlated with metastatic potential in a number of different tumor types. The purpose of this investigation was to examine galectin-3 expression in several tumorigenic and nontumorigenic prostate cell lines and prostate tissue samples.

METHODS. The expression of galectin-3 in cell lines and tissue samples was evaluated by tissue immunohistochemistry and Western blot analysis.

RESULTS. Human cell lines PC-3M, PC-3, DU-145, PrEC-1, and MCF10A demonstrated the presence of galectin-3. Galectin-3 was not detected in TSU-pr1 and LNCaP by Western blot analysis. We furthered our studies by examining a series of human prostate tissue samples for expression of galectin-3. Overall, approximately $60-70 \%$ of the normal tissue examined demonstrated heterogenous expression of galectin-3. In stage II tumors, however, there was a dramatic decrease in galectin-3 expression in both PIN and tumor sections, with only 10.5\% $(2 / 19)$ of these samples expressing this protein. Stage III tumors also demonstrated a decreased expression of galectin-3, although this downregulation was not as dramatic, with 35\% of PIN samples and $52 \%$ of tumor tissue expressing galectin-3 $(P<0.01)$.

CONCLUSIONS. These data demonstrate that galectin-3 is downregulated in prostate cancer. The altered downregulation pattern of galectin-3 observed between tumor stages suggests different roles for galectin-3 in the progression of prostate cancer. Prostate 44:118-123, 2000. (C) 2000 Wiley-Liss, Inc.
\end{abstract}

KEY WORDS: $\quad$ prostate neoplasms; lectin; adhesion molecules

\section{INTRODUCTION}

The most devastating aspect of cancer is the ability of tumor cells to disseminate from their primary site to distant organ metastases. Cancer-related deaths are most often the result of metastatic disease, rather than the primary tumor. Carcinoma of the prostate is the second leading cause of cancer-related deaths in males in the United States. Projected estimates for 1999 indicate that there will be approximately 179,300 newly diagnosed prostate cancers, and that 37,000 men will die from this disease [1]. More than half the number of patients with prostate cancer already have metastases at the time of diagnosis of their disease. Although there has been much advancement and success in the treatment of localized tumors, little has been found in the way of treatment and prevention of metastatic cancer.

For a cancer cell to successfully leave the primary tumor and establish itself in a new organ site requires a complex cascade of events [2]. It involves the inva-

Grant sponsor: University of Michigan Comprehensive Cancer Center; Grant number: P50 CA 69568; Grant sponsor: Dornier Medical Systems, Inc.; Grant sponsor: Zeneca Pharmaceuticals.

${ }^{*}$ Correspondence to: Kenneth J. Pienta, M.D., Division of Hematology and Oncology, Department of Internal Medicine, University of Michigan Comprehensive Cancer Center, 1500 East Medical Center Drive-7308 CCGC, Ann Arbor, MI 48109-0946.

Received 5 August 1999; Accepted 16 March 2000 
sion of the primary tumor into the vasculature, the release of tumor cells or tumor emboli into the circulation, the arrest of these cells in distant organs, and finally the development of these tumor cells into secondary neoplasms. If a tumor fails at any one of these steps, metastasis does not occur.

One of the key steps in metastasis is the interaction between the surface adhesion molecules on tumor emboli and receptor molecules on target organ endothelium [3-6]. These surface adhesion molecules belong to several families of proteins including the integrin, cadherin, immunoglobin, laminin, and lectin families. Galectin-3 (gal-3) is part of a growing family of carbohydrate-binding proteins that fulfill two criteria: 1) affinity for $\beta$-galactosides; and 2) significant sequence homology in the carbohydrate binding site [7]. Gal-3, previously known as CBP-35, Mac-2, L-29, L-34, and L-31, has a monomer Mr of approximately 30,000 and consists of two distinct structural domains: an aminoterminal domain containing a repetitive sequence rich in leucine, tyrosine, and proline residues, and a carboxy terminal domain with a globular structure encompassing the carbohydrate binding site [7-14]. Gal3 , through its interaction with specific ligands, is involved in multiple biological processes, including cell growth, differentiation, inflammation, transformation, metastasis, and adhesion [7-14]. Although the precise role of gal-3 remains to be determined, several studies have demonstrated that gal-3 is upregulated in a variety of human cancers. For example, gal-3 expression was significantly higher in invasive colon cancers as compared to colonic epithelium [15]. Studies have also demonstrated that metastatic tissue expressed higher levels of gal-3 than primary cancers [15]. Expression of gal-3 was upregulated in malignant thyroid neoplasms as compared to thyroid adenomas or normal thyroid tissue, as well as tumors of the central nervous system [16-18]. Alternatively, it has been postulated that gal-3 functions to bind cells to laminin in the extracellular matrix, and loss of this expression correlates with acquisition of an invasive phenotype. Studies in endometrial, colon, and breast cancers demonstrate decreased gal-3 expression as compared to normal cells [19-21]. We previously reported that galectin-3 expression is found in prostate cancer cells, and we postulated that gal-3 was involved in the progression of prostate cancer [22]. The purpose of this study was to examine galectin-3 expression in normal prostate tissue, prostate cancer tissue, and human prostate cancer cell lines.

\section{MATERIALS AND METHODS}

\section{Antibody Production}

A polyclonal antibody to galectin-3 was previously described [23]. Briefly, the galectin-3 gene was isolated from the HT1080 human fibrosarcoma cDNA library (lambda gt11 phage, Clontech, Palo Alto, CA), sequenced, and transferred to the EcoRI site of the bacterial expression vector, pET5b (Promega, Madison, WI). Then, the protein product was extracted from the bacteria cells, put over an asialofetuin column, and eluted with lactose. The elutant was dialysed against water and lyophilized. Afterward, the lyophilized protein was sent to Zymed (San Francisco, CA) for antibody production in rabbits.

\section{Cell Culture}

The MCF10A breast epithelial cell line was maintained in Dulbecco's modified Eagle's medium (DMEM) and F-12 nutrient mixture (1:1; Gibco/BRL, Gaithersburg, MD) supplemented with the following: $5 \%$ equine serum (Gibco/BRL), 1\% antibioticantimycotic solution (Sigma, St. Louis, MO), insulin $\left(10 \mu \mathrm{g} / \mathrm{ml}\right.$; Sigma), cortisol $\left(1.4 \times 10^{-6} \mathrm{M}\right.$; Sigma $)$, cholera enterotoxin $(100 \mathrm{ng} / \mathrm{ml}$; ICN Biomedicals, Cleveland, $\mathrm{OH})$, and epidermal growth factor $(20 \mathrm{ng} / \mathrm{ml}$; Gibco/BRL) [24]. The human prostate epithelial cell line, PrEC-I, was obtained from Clonetics (San Diego, CA) and immortalized in our laboratory, using the SV-40 large $\mathrm{T}$ antigen as previously described [25]. This cell line was maintained in DMEM supplemented with $10 \%$ fetal bovine serum (FBS; Gibco/BRL) and $1 \%$ antibiotic-antimycotic solution. The prostate cell line TSU-PR1 was obtained from J. Isaacs (Johns Hopkins, Baltimore, MD) [26]. The human prostate cancer cell lines PC3, DU145, and LNCaP were obtained from the American Type Culture Collection (ATCC, Rockville, MD) [27-30]. The human prostate cancer cell line PC3 Bone, which metastasizes preferentially to bone tissue, was obtained from Mark Stearns, Ph.D (University of Pennsylvania) [31]. TSU-PR1, DU-145, PC3 Bone, PC3, and LNCaP were maintained in RPMI1640 media containing $10 \%$ FBS and $1 \%$ antibioticantimycotic solution.

\section{Western Blot Analysis}

Aliquots of whole-cell lysates were resolved by electrophoresis on a 10\% SDS-polyacrylamide gel, using standard procedures. After electrophoresis, the gels were submerged in transfer buffer (192 mM glycine and $0.25 \mathrm{mM}$ Trizma base, $\mathrm{pH}$ 8.3) and allowed to equilibrate for $30 \mathrm{~min}$. Proteins were then transferred to a Hybond ECL nitrocellulose membrane (Amersham Life Sciences, Buckinghamshire, UK) for $1 \mathrm{hr}$ at $4^{\circ} \mathrm{C}$ at 100 volts using a BioRad Mini Protean II Transfer Unit (BioRad, Hercules, CA). For Western blotting, the ECL Western Blotting Detection Kit was used (Amersham Life Sciences). The detection system uses a chemiluminescent reagent that is cleaved by horse- 


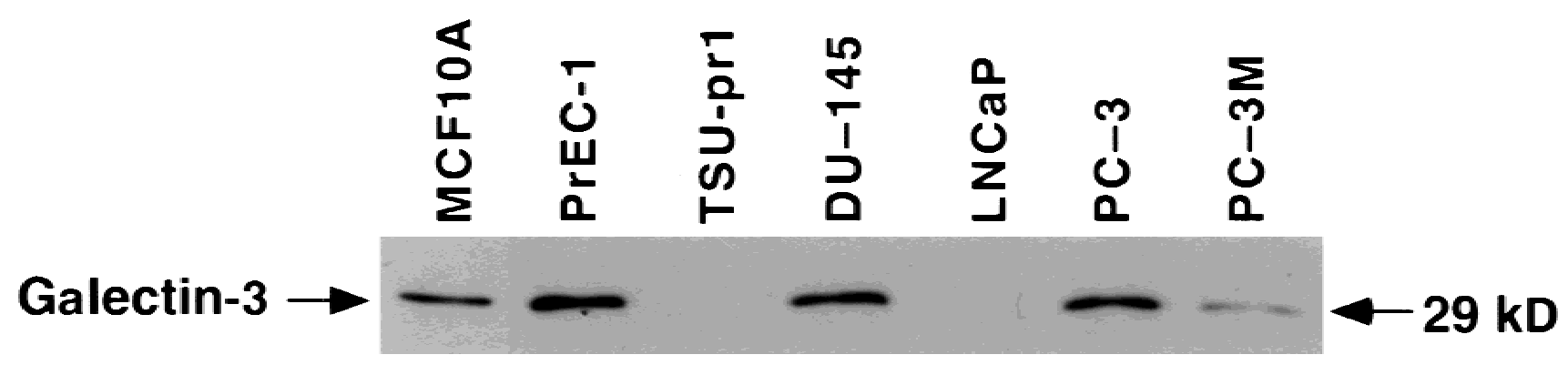

Fig. I. Expression of galectin-3 in human cell lines. Whole-cell lysates were extracted from described cultures and analyzed for galectin-3 expression according to the procedures outlined in Materials and Methods. The following human cell lines were analyzed for the 29,000-kDa protein: MCFIOA (positive control), PrEC-I, TSU, DU-I45, LNCaP, PC3, and PC-3M (PC3 Bone).

radish peroxidase (tethered to the secondary antibody) and produces a signal easily detected using standard X-ray film. All reagents were obtained from Amersham Life Sciences. After transfer, the membrane was submerged in a $10 \%$ milk solution for $1 \mathrm{hr}$ to block any nonspecific binding. The membrane was then washed quickly in PBS with $0.1 \%$ Tween 20 (PBST), followed by a 15-min wash in PBST and two 5-min washes in PBST. The membrane was incubated for $1 \mathrm{hr}$ at room temperature with a primary antibody (rabbit anti-human galectin-3: $1 \mathrm{mg} / \mathrm{ml}$ in stock solution) at a final concentration of $300 \mu \mathrm{g} / \mathrm{ml}$ and washed as stated above in PBST. The membrane was then incubated for $30 \mathrm{~min}$ at room temperature with secondary antibody (sheep anti-rabbit Ig horseradish peroxidase-linked whole antibody, Amersham Life Sciences; $0.125 \mu \mathrm{g} / \mathrm{ml}$ ) and washed once in PBST for $15 \mathrm{~min}$, followed by four 5-min washes in PBST. After the final wash, galectin-3 was detected using the ECL kit, following the manufacturer's instructions. X-ray film was placed over the membrane, and the film was exposed for different time periods for optimum visualization.

\section{Prostate Tissue Immunohistochemistry}

A modification of the biotin-avidin complex method was used to determine the distribution of galectin-3 in 39 matched paraffinized normal and prostate cancer tissue samples obtained from the University of Michigan Tissue Procurement Core. All samples had been previously verified by a pathologist (K.J.W.). Samples were first deparaffinized by twice incubating in xylene for $5 \mathrm{~min}$, ethanol for $3 \mathrm{~min}$, and $90 \%$ ethanol for $3 \mathrm{~min}$. Afterwards, slides were placed in a $0.01 \mathrm{M}$ PBS solution. Tissue section pairs were incubated in an $8 \%$ goat serum solution in $0.01 \mathrm{M}$ PBS for $20 \mathrm{~min}$ at room temperature to block nonspecific binding. The blocking solution was then removed, and $0.2 \mathrm{mg} / \mathrm{ml}$ of the gal-3 antibody in 0.01 M PBS were added to one of the tissue sections for $2 \mathrm{hr}$ at room temperature. The other tissue section pair was incu- bated in 0.01 M PBS only to detect any nonspecific binding.

The gal-3 antibody solution was removed and tissue sections were quickly rinsed twice with $0.01 \mathrm{M}$ PBS, and then washed twice for $5 \mathrm{~min}$ with $0.01 \mathrm{M}$ PBS. An anti-rabbit biotinylated secondary antibody from the VECTASTAIN Elite Immunodetection Kit (Vector Laboratories, Burlingame, CA) was added to the tissue sections and allowed to incubate for $30 \mathrm{~min}$, followed by two quick washes and two 5-min washes with 0.01 M PBS. Vectastain ABC complexing reagent was then added to each tissue section and allowed to incubate for $30 \mathrm{~min}$, followed by two quick rinses and two 5-min washes with 0.01 M PBS. Immunodetection of galectin-3 on the tissue sections was visualized by using the Vector peroxidase substrate kit (DAB kit). Tissue sections were counterstained with hematoxylin for $2 \mathrm{~min}$, followed by incubation of tissue sections in $95 \%$ ethanol for 3 min twice, ethanol for 3 min twice, and xylene for 3 min twice. Coverslips were mounted using Permount (Fisher, Pittsburgh, PA).

Stained specimens were scored by two independent observers on a scale ranging from $0-3$, with 0 indicating a lack of stain and 3 indicating the presence of intense staining. Observations took into account the difference in staining between prostate intraepithelial neoplasia (PIN), tumor, normal epithelial, and basalcell layers.

\section{RESULTS}

\section{Expression of Galectin-3 in Prostate Cells}

We first examined the pattern of expression of gal-3 in a series of nontumorigenic and tumorigenic prostate cell lines by Western blot analysis (Fig. 1). Lysates extracted from each cell line demonstrated the presence of a $29,000-\mathrm{kDa}$ protein in the following cell lines: MCF10A, PrEC-1, DU-145, PC-3, and PC-3M. Despite numerous attempts, TSU-PR1 and LnCAP cell lines did not demonstrate gal-3 expression (Fig. 1). There appears to be no significant difference in 
TABLE I. Galectin-3 Expression in Prostate Tissue

\begin{tabular}{lcc}
\hline Cell type & $\begin{array}{c}\text { Stage 2 } \\
(\%)^{\mathrm{a}}\end{array}$ & $\begin{array}{c}\text { Stage 3-4 } \\
(\%)^{\mathrm{b}}\end{array}$ \\
\hline Normal epithelial & $89(17 / 19)$ & $62(12 / 20)$ \\
Normal basal & $45(9 / 17)$ & $55(11 / 20)$ \\
PIN2 & $10.5(2 / 19)$ & $35(7 / 20)$ \\
Tumor & $10.5(2 / 19)$ & $50(10 / 20)$ \\
\hline
\end{tabular}

a\% is defined as percentage of samples which expressed galectin-3 by immunocytochemical staining. Positive samples were determined by two independent observers. Nineteen tissue samples from stage II patients and 20 tissue samples from stage III patients were analyzed.

${ }^{\mathrm{b}} \mathrm{PIN}$, prostatic intraepithelial neoplasia.

gal-3 protein expression when comparing protein expression in the nontumorigenic PREC- 1 cell line to the tumorigenic cell lines examined.

\section{Expression of Galectin-3 in Human Prostate Tissues}

We next examined the tissue staining pattern of normal, premalignant, and malignant prostate tissue from 39 patients who had undergone radical prostatectomy for stage II (19 patients) and III (20 patients) prostate cancer. In stage II disease, 17/19 normal tissue samples demonstrated positive staining of their epithelial cells, and 8/19 samples demonstrated positive staining of their basal cells (Table I and Fig. 2). Galectin-3 expression in atrophic glands was similar to galectin-3 expression in normal glands (Fig. 2). The expression of galectin-3 within the epithelial cells was very heterogeneous, with $10 / 19$ showing weak expression of galectin-3, 6/19 demonstrating moderate expression, and 1/19 demonstrated strong expression of galectin-3 throughout the sample. In patients with stage III disease, epithelial cells and basal cells stained positive for galectin-3 in 12/19 and 11/19 of normal tissue samples, respectively. This pattern was similar to the heterogeneous pattern demonstrating positive staining observed in the stage II samples. Approximately $10 \%(2 / 19)$ of prostatic intraepithelial neoplasia (PIN) specimens in the patients with stage II prostate cancer stained positive for gal-3, while 35\% (7/19) of specimens from stage III patients demonstrated galectin-3 expression. PIN appeared to only stain positively in patients' samples with Gleason grade tumors of 7 or less. Only $10.5 \%(2 / 19)$ of stage II tumors demonstrated gal-3 staining, while $52 \%(10 / 19)$ of stage III tumors stained positive $(P<0.01)$. Positive staining was often focal and intense in tumors, suggesting that subpopulations of cells were staining differently. Staining in tumors did not correlate with Gleason grade. Atrophic cells in all specimens stained intensely.

\section{DISCUSSION}

It has been demonstrated that gal-3 has a variety of functions in the cell, ranging from binding to the nuclear matrix to acting as a substrate for matrix metalloproteinases. On the cell surface, gal-3 has been demonstrated to bind laminin in the extracellular matrix. Previous reports are contradictory, suggesting that gal-3 may be upregulated or downregulated as a cell requires a tumorigenic phentoype. Some reports suggest that downregulation of gal-3 in conjunction with dissolution of the basement membrane through upregulation of metalloproteinases would allow tumor cells to disseminate. Conversely, upregulation of gal-3 in metastatic cells could allow greater adhesion to target organ endothelial cells. In the present study, we examined several prostate cell lines as well as human prostate tissue to determine the galectin- 3 expression pattern in these samples. All cell lines, with the exception of TSU-PR1 and LnCAP, demonstrated gal-3 expression by Western blot analysis. Western blot analysis failed to demonstrate the presence of galectin-3 in both LnCaP and TSU-PR1 cultures. These results are consistent with recently reported results examining expression of galectin-3 in human prostate cell lines [32]. No change in in vitro expression of galectin-3 was observed by Western blot analysis of lysates between the nontumorigenic line PREC-1 and the tumorigenic lines examined.

Examination of the expression of galectin-3 in human prostate tissue, however, yielded interesting results. Prostate tissue samples from 39 patients containing a tumor tissue sample and matched control samples were stained for galectin-3 expression. Overall, approximately $60-70 \%$ of the normal tissue examined demonstrated heterogenous expression of galectin-3. It is conceivable that this heterogenous expression of galectin-3 in normal tissue could be influenced by proximal tumor tissue. However, this notion was not further explored in this study. In stage II tumors, there was a dramatic decrease in galectin-3 expression in both PIN and tumor sections, with only $10 \%$ of these samples expressing this protein. Positive staining was often focal and intense in tumors, suggesting that subpopulations of the cells were staining differently. Stage III tumors also demonstrated a decreased expression of galectin-3, although this decrease was not as dramatic, with $35 \%$ of PIN samples and $50 \%$ of tumor tissue expressing galectin-3.

\section{CONCLUSIONS}

These observations are consistent with previous reports demonstrating a decrease in galectin-3 expres- 


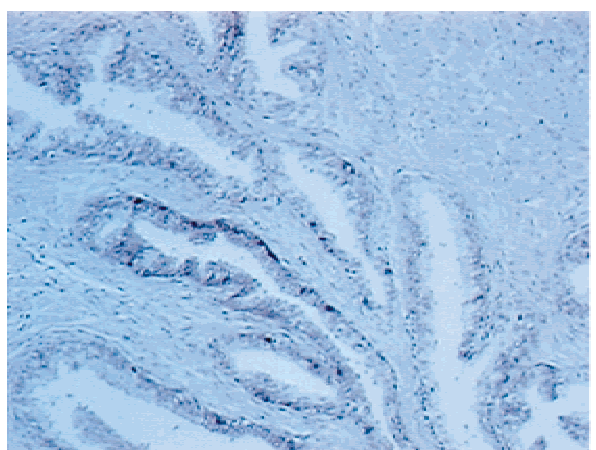

A

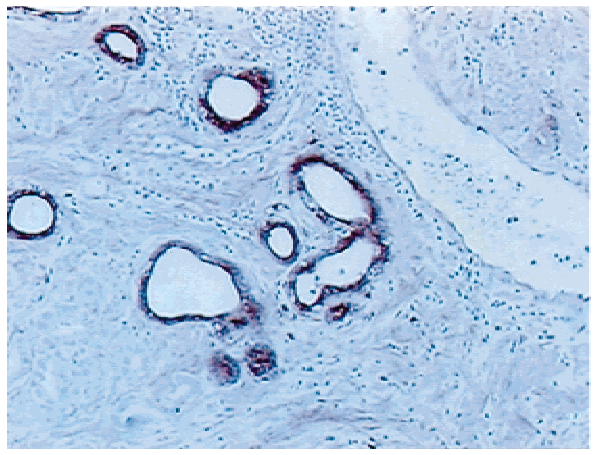

C

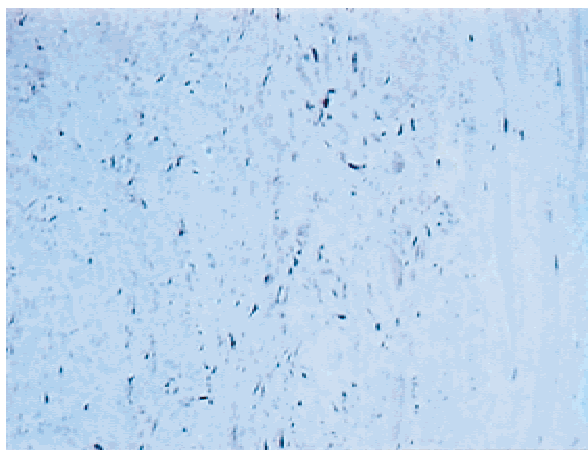

E

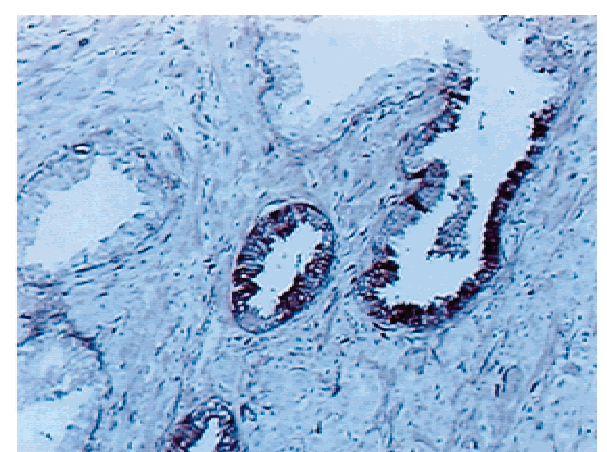

B

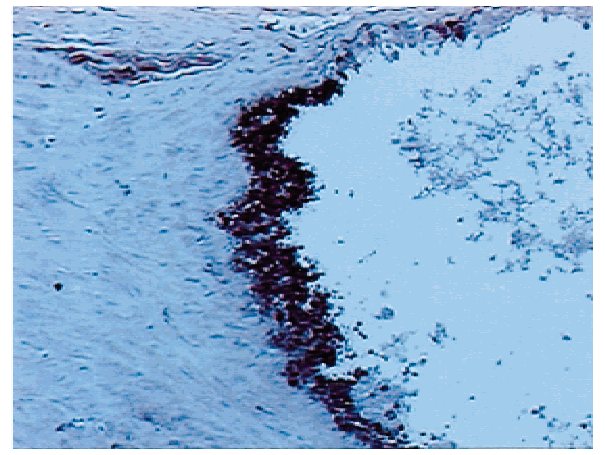

D

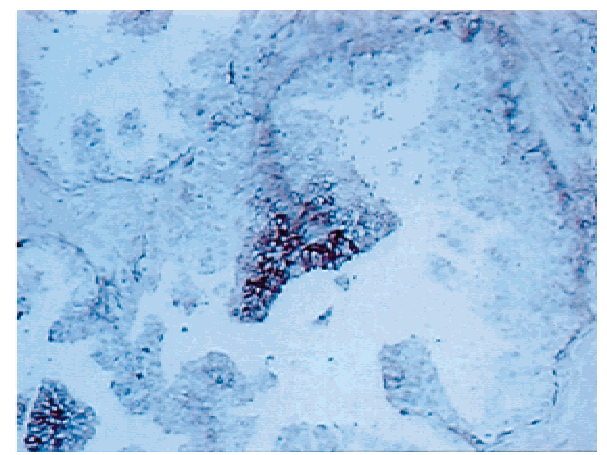

F

Fig. 2. Expression of galectin-3 in human prostate tissue. Samples were subjected to immunohistochemistry, using a polyclonal antibody to galectin-3 as described in Materials and Methods. Pictures were taken at a magnification of $\times 10$. Staining of cells was heterogeneous; examples are given here of $(\mathbf{A})$ basal cells, (B) epithelial cells, (C) atrophic, (D) PIN, (E) focal tumor, and (F) patchy tumor.

sion in endometrial, breast, and ovarian cancers $[19,20,33]$. Although this is controversial, other investigations have shown an increase in galectin-3 in malignant progression $[15,21]$. Other reports also demonstrate that increased expression of galectin-3 is associated with high metastatic potential [15-18]. Our results, combined with those previously reported, suggest that the role of galectin-3 in tumorigenesis may be dependent on cell type. Furthermore, our data support the notion that galectin-3 may play a different role in tumor progression depending on tumor stage. Our data do not clearly indicate that a dramatic de- crease is observed in tumors of all stages, as those of higher stage demonstrated only slight, albeit statistically significant $(P<0.01)$ decreased expression. This phenomenon may also explain the lack of expression of galectin-3 observed in LnCaP and TSU-Prl cultures. Alternatively, this lack of expression in $\mathrm{LnCaP}$ and TSU-Pr1 cultures or the expression of galectin-3 in the other cell lines examined could be attributed to cultural artifacts. Further studies are warranted to examine the expression pattern of galectin-3 in more tumor specimens to determine the role of galectin-3 expression in prostate cancer progression. 


\section{ACKNOWLEDGMENTS}

We gratefully acknowledge the secretarial assistance of Marty Merris-Davis and Jasmine Bhatia. This work was supported by SPORE grant P50 CA 69568 at the University of Michigan Comprehensive Cancer Center. M.J.P. and C.R.C. are supported by 1997 and 1999 American Foundation for Urological Disease Fellowships sponsored by Dornier Medical Systems, Inc., and Zeneca Pharmaceuticals, respectively.

\section{REFERENCES}

1. Landis SH, Murray T, Bolden S, Wingo PA. Cancer statistics. CA Cancer J Clin 1999;49:8-31.

2. Liotta LA. Cancer cell invasion and metastasis. Sci Am 1992;266: 54-63.

3. Kohn EC, Liotta LA. Invasion and metastasis: new approaches to an old problem. Oncology 1993;7:47-62.

4. Albelda SM. Biology of disease: role of integrins and other cell adhesion molecules in tumor progression and metastasis. Lab Invest 1993;68:4-17.

5. Stetler-Stevenson WG, Aznavoorian S, Liotta LA. Tumor cell interactions with the extracellular matrix during invasion and metastasis. Annu Rev Cell Biol 1993;9:541-573.

6. Bussemakers MJG, Schalken JA. The role of cell adhesion molecules and proteases in tumor invasion and metastasis. World J Urol 1996;14:151-156.

7. Barondes SH, Cooper DN, Gitt MA, Leffler H. Galectins: structure and function of a large family of animal lectins. J Biol Chem 1994;269:20807-20810.

8. Konstantinov KN, Robbins BA, Liu FT. Galectin-3, a betagalactoside-binding animal lectin, is a marker of anaplastic large-cell lymphoma. Am J Pathol 1996;148:25-30.

9. Moutsatsos IK, Wade M, Schnidler M, Wang JL. Endogenous lectins from cultured cells: nuclear localization of carbohydratebinding protein 35 in proliferating $3 \mathrm{~T} 3$ fibroblasts. Proc Natl Acad Sci USA 1987;84:6452-6456.

10. Woo HJ, Shaw LM, Messier JM, Mercurio AM. The major nonintegrin laminin binding protein of macrophage is identical to carbohydrate binding protein 35 (Mac-2). J Biol Chem 1990;265: 7097-7109.

11. Inohara $H$, Akahani $S$, Koths $K, \operatorname{Raz} A$. Interactions between galectin-3 and Mac-2-binding protein mediate cell-cell adhesion. Cancer Res 1996;56:4530-4534.

12. Frugeri LG, Liu FT. Surface expression of functional IgE binding protein, an endogenous lectin, on mast cells and macrophages. J Immunol 1992;148:861-867.

13. Liu FT. S-type mammalian lectins in allergic inflammation. Immunol Today 1993;14:486-490.

14. Inohara H, Raz A. Functional evidence that cell surface galectin-3 mediates homotypic cell adhesion. Cancer Res 1995;55: 3267-3271.

15. Schoeppner HL, Raz A, Ho SB, Bresalier RS. Expression of an endogenous galactose-binding lectin correlates with neoplastic progression in the colon. Cancer 1995;75:2818-2826.

16. Xu X, El-Naggar AK, Lotan R. Differential expression of galectin-1 and galectin-3 in thyroid tumors: potential diagnostic implications. Am J Pathol 1995;147:815-822.

17. Bresalier RS, Yan P-S, Byrd JC, Lotan R, Raz A. Expression of the endogenous galactose-binding protein galectin-3 correlates with the malignant potential of tumors in the central nervous system. Cancer 1997;80:776-787.

18. Fernandez PL, Merino MJ, Gomez M, Campo E, Medina T, Castronovo V, Sanjuan X, Cardesa A, Liu FT, Sobel ME. Galectin-3 and laminin expression in neoplastic and non-neoplastic thyroid tissue. J Pathol 1997;181:80-86.

19. Castronovo V, Van Den Brule FA, Jackers P, Clausse N, Liu F, Gillet C, Sobel ME. Decreased expression of galectin-3 is associated with progression of human breast cancer. J Pathol 1996; 179:43-48.

20. Van Den Brule FA, Buicu C, Berchuck A, Bast C, Deprez M, Liu FT, Cooper DN, Pieters C, Sobel ME, Castronovo V. Expression of the $67-\mathrm{kD}$ laminin receptor, galectin-1, and galectin-3 in advanced human uterine andenocarcinoma. Hum Pathol 1996;27: 1185-1191.

21. Lotz MM, Andrews CW Jr, Korzelius CA, Lee EC, Steele GD Jr, Clarke A, Mercurio AM. Decreased expression of Mac-2 (carbohydrate binding protein 35) and loss of its nuclear localization are associated wit the neoplastic progression of colon carcinoma. Proc Natl Acad Sci USA 1993;90:3466-3470.

22. Wang L, Inohara $\mathrm{H}$, Pienta KJ, Raz A. Galectin-3 is a nuclear matrix protein which binds RNA. Biochem Biophys Res Commun 1995;217:292-303.

23. Inohara $\mathrm{H}, \mathrm{Raz} \mathrm{A}$. Identification of human melanoma cellular and secreted ligands for galectin-3. Biochem Biophys Res Commun 1994;201:1366-1375.

24. Soule HD, Maloney TM, Wolman SR, Peterson WD, Brenz R, McGrath CM, Russo J, Pauley RJ, Jones RF, Brooks SC. Isolation and characterization of a spontaneously immortalized breast epithelial cell line, MCF-10. Cancer Res 1990;50:6075-6086.

25. Yamazaki K, Lehr JE, Rhim JS, Pienta KJ. Establishment of an immortalized Copenhagen rat bone marrow endothelial cell line. In Vivo 1996;10:459-462.

26. Iizumi T, Yazaki T, Kanoh S, Kondo I, Koiso K. Establishment of a new prostatic carcinoma cell line (TSU-PR1). J Urol 1987;137: 1304-1306.

27. Mickey DD, Stone KR, Wunderli H, Mickey GH, Vollmer RT, Paulson DF. Heterotransplantation of a human prostatic adenocarcinoma cell line in nude mice. Cancer Res 1977;37:4049-4058.

28. Ohnuki Y, Marnell MM, Babcock MS, Lechner JF, Kaighn ME. Chromosomal analysis of human prostatic adenocarcinoma cell lines. Cancer Res 1980;40:524-534.

29. Kaighn ME, Narayan KS, Ohnuki Y, Lechner JF, Jones LW. Establishment and characterization of a human prostatic carcinoma cell line (PC-3). Invest Urol 1979;17:16-23.

30. Horoszewicz JS, Leong SS, Chu TM, Wajsman ZL, Friedman M, Papsidero L, Kim U, Chai LS, Kakati S, Arya SK, Sandberg AA. The LNCaP cell line- a new model for studies on human prostatic carcinoma. Prog Clin Biol Res 1980;37:115-132.

31. Wang M, Stearns ME. Isolation and characterization of PC-3 human prostatic tumor sublines which preferentially metastasize to select organs in S.C.I.D. mice. Differentiation 1991;48: $115-125$.

32. Ellerhorst J, Nguyen T, Cooper DN, Lotan R, Lotan D. Differential expression of endogenous galectin- 1 and galectin- 3 in human prostate cancer cells lines and effects of overexpressing galectin-1 on cell phenotype. Int J Oncol 1999,14:217-224.

33. van den Brule FA, Berchuck A, Bast RC, Liu FT, Gillet C, Sobel $\mathrm{ME}$, Castronovo V. Differential expression of the $67 \mathrm{kD}$ laminin receptor and $31 \mathrm{kD}$ human laminin binding protein in human ovarian carcinomas. Eur J Cancer 1994;30:1096-1099. 